\title{
Voltage Control of Intermittent Pulse Density Modulation for Two Battery-operated HEECS Choppers and its Application for Range Extension of Electric Vehicles
}

\author{
Ayataro Tamura* Student Member, \\ Takayuki Ishibashi* \\ Student Member \\ Takuro Umihara* Student Member, \\ Yukinori Tsuruta* \\ Member \\ Hidemine Obara* Member, \\ Atsuo Kawamura* \\ Fellow
}

(Manuscript received Nov. 15, 2018, revised March 4, 2019)

\begin{abstract}
This paper proposes voltage control of two battery-operated high-efficiency energy conversion system choppers, which have a very high efficiency of $99.3 \%$ and are suitable for power trains of electrical vehicles. However, due to the topology of the choppers, one disadvantage is that the chopper output voltage control has a large transient response, for example, when the duty ratio is changed from zero to a finite value, because of the inherent dead time in the switching phenomena. The minimum pulse width of the gate signal is physically determined by the delay time in the switching phenomena. As a result, there exists a dead time when the duty ratio is changed in this case. Similar phenomena occur when the duty ratio is changed around unity. Consequently, an overcurrent is observed during these types of transient periods and the system shuts down due to overcurrent protection. To solve this problem, intermittent pulse density modulation is proposed such that the output voltage is controlled by the average duty ratio. This makes it possible to output both the very low and the very high average duty ratios with multiple sampling periods. As a result, the transient response was experimentally verified to be improved even though the voltage ripple under this control increased compared with that under simple pulse width modulation (PWM) control.
\end{abstract}

Keywords: voltage control, electric vehicle, power train, buck chopper, motor test bench, power electronics

\section{Introduction}

The use of a greater number of electric vehicles (EVs) is said to be one of the solutions to environmental problems such as global warming; however, EVs have the disadvantage of a short driving range for a given battery capacity when compared with internal combustion engine vehicles.

Several approaches for driving range extension have been investigated such as the optimization of motor control ${ }^{(1)}$ or the use of a new power train ${ }^{(2)-(7)}$. Figure 1 depicts a typical EV power train, which may be called a "non-chopper" type power train. This structure is very simple. Because the inverter input voltage is fixed by the battery voltage, the switching loss is proportional to the input voltage. For inverter loss reduction, a series-chopper-based power train has been proposed $^{(4)-(7)}$, in which a DC-DC converter is inserted between the battery and inverter, and the inverter input voltage is controlled according to the motor speed. A higher efficiency chopper, called a two-battery High Efficiency Energy Conversion System (HEECS) chopper based on a partial booster circuit, has been proposed ${ }^{(8)}$. The efficiency of the HEECS is higher than $99.3 \%$ over a wide operating range ${ }^{(8)}$. Driving energy consumption is reduced by the HEECS chopper-based power train compared with typical $\mathrm{EV}$ power trains in driving

\footnotetext{
* Graduate School of Engineering, Yokohama National University 79-5, Tokiwadai, Hodogaya-ku, Yokohama, Kanagawa 2408501, Japan
}

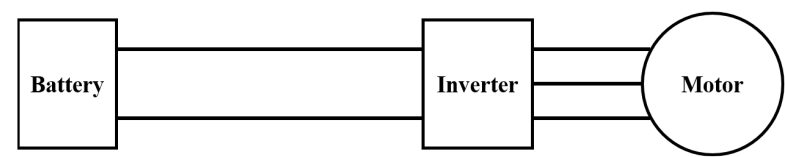

(a) Non-chopper type power train

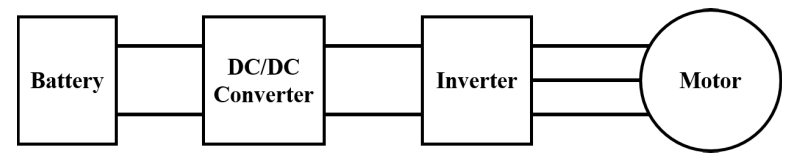

(b) Series-chopper-based power train

Fig. 1. Power trains for electric vehicles ${ }^{(2)}$

cycle tests ${ }^{(6)}$.

However, the chopper output-voltage control has a large transient response when the duty ratio is changed from zero to a finite value, and when it is changed from a finite value to zero. This phenomenon is called a limit cycle oscillation. This large transient voltage switching initiates the overcurrent protection and the system shuts down. The same phenomenon occurs when the duty ratio becomes exactly unity.

This study presents a solution to this problem by a proposed intermittent pulse-density control. This paper is organized as follows: section 2 explains the basic operation of the two-battery HEECS chopper. In section 3, the proposed intermittent voltage control method is shown, and its effect is analyzed. In section 4 , the simulations of step responses and frequency characteristics are shown and compared with 


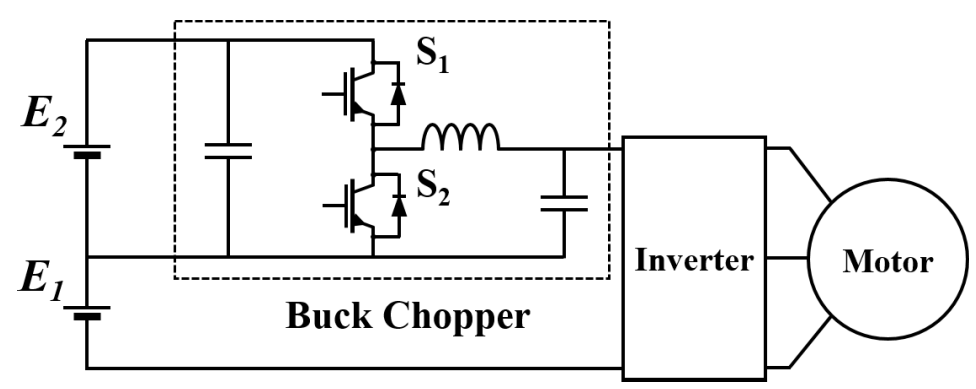

Fig. 2. Power train using two-battery HEECS chopper $^{(6)}$
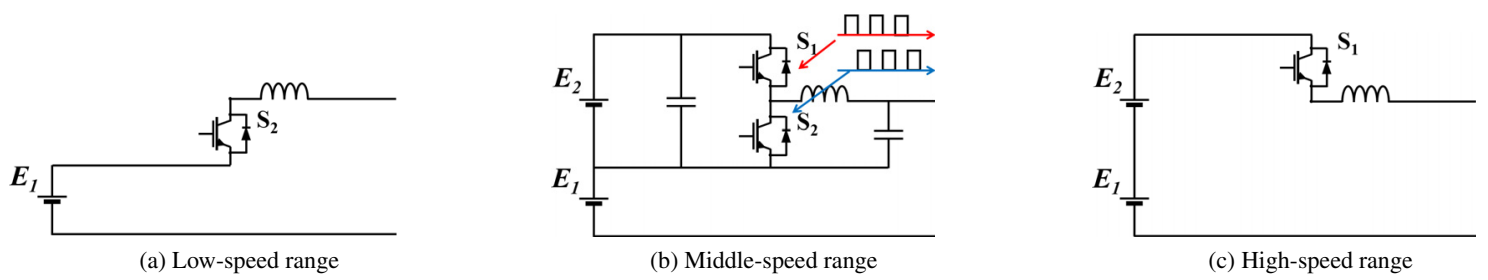

Fig. 3. Basic operation of two-battery HEECS chopper ${ }^{(6)}$

experimental results. In section 5, experiments of range extension of electric vehicles are described. Finally, section 6 summarizes the conclusions.

\section{Operation Modes of Two-battery High Effi- ciency Energy Conversion System Chopper- based Power Train}

The two-battery HEECS chopper consists of two voltage sources and one buck chopper as shown in Fig. 2. Figure 3 shows the three typical operation modes of this chopper. In a low-speed range, the HEECS chopper outputs only battery voltage $E_{1}$ as shown in Fig. 3(a). In a middle-speed range, the HEECS chopper output voltage is the sum of battery voltage $E_{1}$ and the buck chopper output voltage as shown in Fig. 3(b). In a high-speed range, HEECS chopper outputs battery voltage $E_{1}$ plus battery voltage $E_{2}$ as shown in Fig. 3(c).

The output voltage $\mathrm{V}_{\text {HEECS }}$ and efficiency $\eta_{H E E C S}$ of the HEECS chopper are expressed as

$$
\begin{aligned}
V_{H E E C S} & =E_{1}+d E_{2}, \cdots \\
\eta_{H E E C S} & =\frac{P_{1}+\eta_{\text {chop }} P_{2}}{P_{1}+P_{2}},
\end{aligned}
$$

where $E_{1}, E_{2}, d, P_{1}, P_{2}$, and $\eta_{\text {chop }}$ represent the voltage of $E_{1}$, the voltage of $E_{2}$, the duty ratio, the output power of $E_{1}$, the output power of $E_{2}$ and the efficiency of the buck chopper, respectively. In a low-speed range, the duty ratio is set to $d=$ 0 and in a high-speed range, the duty ratio is set to $d=1$. Thus, the overall efficiency of the HEECS is higher than the efficiency of the chopper and the HEECS efficiency is over $99 \%{ }^{(8)-(10)}$.

\section{Basic Operation of the Chopper-based Power Train and a Problem During the Actual Oper- ation}

\subsection{Basic Operation of Chopper-based Power Train} The DC link voltage, which has a constant DC voltage in the low speed range, is controlled as shown in Fig. 4. After a certain speed, the DC link voltage is increased proportionally to the speed, and it becomes a constant at a certain high speed. This DC voltage profile results in an approximately

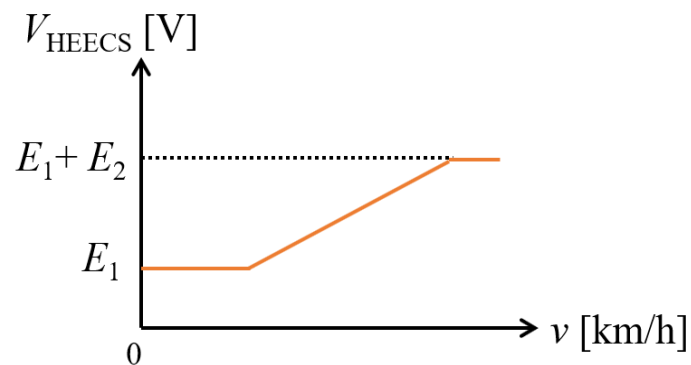

Fig. 4. DC link voltage profile of chopper-based power train

5-6\% driving range extension compared with a non-chopper type power train ${ }^{(6)}$.

The two-battery HEECS chopper-based power train has two batteries, and State of Charge (SoC) imbalance occurs without any special control. Thus, a control to improve the SoC imbalance has been proposed by the authors ${ }^{(11)(12)}$.

3.2 Minimum Pulse and Maximum Pulse Width Problem Due to the nature of the HEECS chopper, there is a problem in the transition operation mode between the duty ratio of zero and a finite minimum value, and between a high duty ratio and unity. A smooth output voltage control of this HEECS chopper is required as shown in Fig. 4, particularly from the constant voltage $E_{1}$ to a higher output value or from the high output voltage to the constant voltage $\left(E_{1}+E_{2}\right)$.

During this transition, the actual duty ratio should change from zero to a very small value. However, the actual achievable pulse width is equal to the minimum duty ratio, for example, 0.06 times the sampling period, due to the dead time of the actual switching devices. We define this as the hardware minimum one pulse width $T_{\min }$ and, correspondingly, the duty ratio for the same is $d_{\text {min }}$. Similarly, we define $d_{\text {max }}$ as a possible hardware maximum duty ratio less than unity by one pulse.

The vehicle speed may change in any manner that a driver controls the vehicle speed, thus sometimes a so-called limit cycle may occur if the difference between zero duty ratio and the minimum duty ratio $d_{\min }$ is not small enough. To avoid this, a speed dead zone is introduced; however, this dead zone 


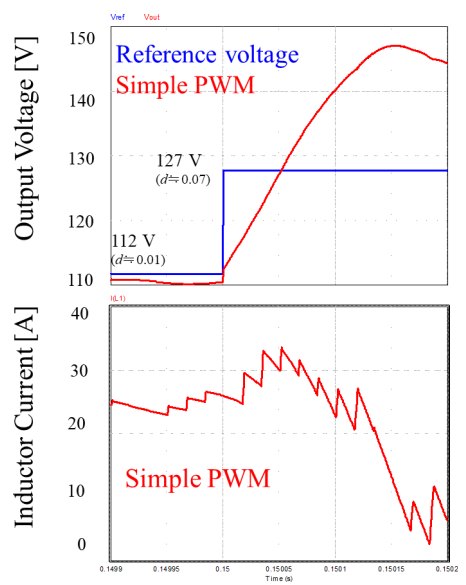

Fig. 5. Step response of HEECS chopper in simulation for simple pulse width modulation (PWM)

degrades the transfer function characteristic of the chopper performance. In addition, the change of duty ratio from zero to $d_{\min }$ often introduces a transient overcurrent of the chopper combined with the limit cycle. Figure 5 shows the step response of the HEECS chopper output voltage command. A large transient inductor current is observed. If this overcurrent occurs, the chopper controller stops the operation to protect against damage to the switching device. It is necessary to increase the rating of the device to avoid this phenomenon. A similar result occurs when the duty ratio changes from $d_{\text {max }}$ to unity. To solve this problem, an intermittent pulse density modulation (PDM) is proposed in the next section.

3.3 Intermittent Pulse Density Modulation ${ }^{(14)-(16)}$ In this section, the control method of intermittent PDM is explained. The sampling frequency and switching frequency are both $60 \mathrm{kHz}$ and the sampling time is about $17 \mu \mathrm{s}$ in this study. The control method is designed to output a required duty ratio as an average value by using intermittent output pulses.

As an example, intermittent control for five sampling intervals can be explained as follows. If $d=0.02$ is required, we try to set the average duty ratio equal to 0.02 by averaging five duty ratio pulses as in the sequence " $0.1,0,0,0,0$ ". Over this interval, the whole sampling frequency is $60 \mathrm{kHz} / 5=12 \mathrm{kHz}$ and the whole sampling period is $17 \mu \mathrm{s} \times 5=85 \mu \mathrm{s}$. Using this method, it is possible to output the region of $0<d<0.06$, which cannot be output by one pulse because of the switching dead time. As the number of sampling intervals required for one intermittent control increases, the resolution of the duty ratio becomes minute, but the control itself needs a longer time. Thus, it is necessary to choose the appropriate number of sampling intervals.

\subsubsection{Intermittent Pulse Density Modulation Algo-} rithm When the duty ratio command $d_{P I}$ from the PI controller in Fig. 6 is below the minimum duty ratio $d_{\text {min }}$, the pulse number $p$ is calculated as follows,

$$
p=\frac{d_{P I}}{d_{\min } / n}
$$

where $n$ is the total pulse number for an intermittent PDM set; $n$ is selected to be 16 in this study. The concrete pulse density pattern is shown in Table 1 . For example, if $p=2$ is calculated from (3), the pulse pattern in sequence is " $d_{\min }$,

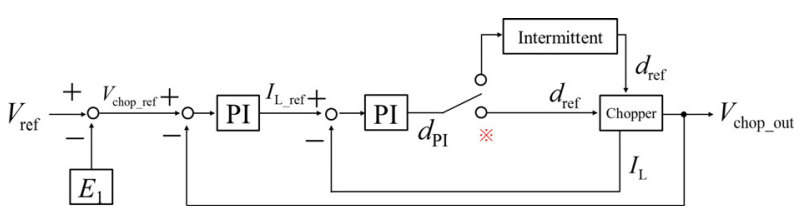

Fig. 6. Control block diagram of intermittent PDM

Table 1. Output pulse pattern of the intermittent PDM

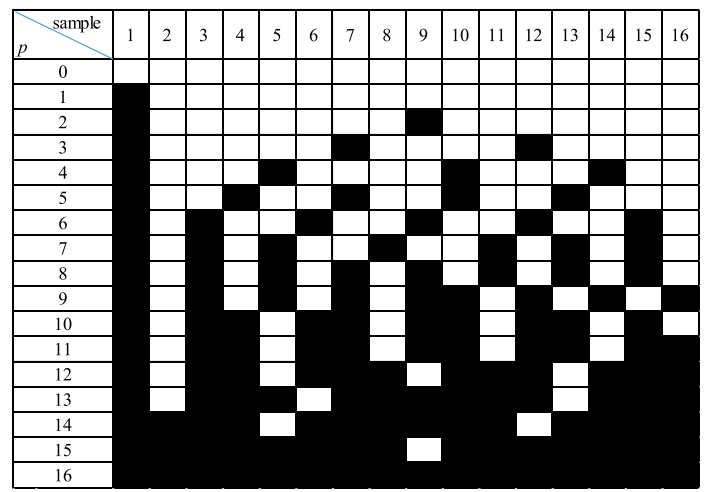

The column is $p$ in (3) and the row shows the $i$-th pulse in $(n=16)$ pulses $(i=1,2, \cdots$ $n$ ). When the duty ratio is very small, the black block means the duty $d_{\min }$, and white block means the duty 0 . When the duty ratio is around unity, the white block means $d_{\max }$, and black block is unity.

Table 2. Definitions of variables in the block diagram

\begin{tabular}{|l|l|}
\hline Voltage reference [V] & $V_{\text {ref }}$ \\
\hline Chopper output voltage reference [V] & $V_{\text {chop_ref }}$ \\
\hline Chopper output voltage [V] & $V_{\text {chop_out }}$ \\
\hline Inductor current reference [A] & $I_{L_{-} \text {ref }}$ \\
\hline Inductor current [A] & $I_{L}$ \\
\hline PI controller calculation duty ratio & $d_{P I}$ \\
\hline duty ratio reference & $d_{\text {ref }}$ \\
\hline
\end{tabular}

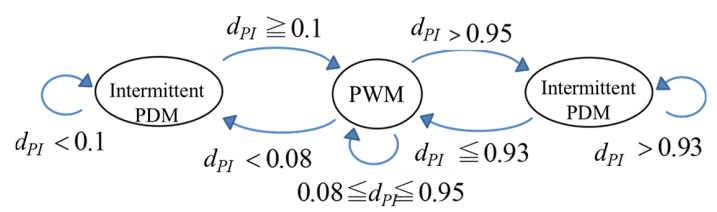

Fig. 7. Hysteresis control and state transition map of intermittent PDM control

$0,0,0,0,0,0,0, d_{\min }, 0,0,0,0,0,0,0 \%$. We may investigate a new PDM pattern if the harmonics contents during the intermittent PDM operation have some restrictions.

Similarly, the intermittent PDM around the duty ratio $d=$ 1 is obtained. When the duty ratio command $d_{P I}$ is above the maximum duty ratio $d_{\max }$, the pulse number is calculated as follows.

$$
p=\frac{\left(1-d_{P I}\right)}{\left(1-d_{\max }\right) / n} .
$$

In this case, if $p=2$ is calculated from (4), the pulse pattern sequence is " $1, d_{\text {max }}, d_{\text {max }}, d_{\text {max }}, d_{\text {max }}, d_{\text {max }}, d_{\text {max }}, d_{\text {max }}, 1$, $d_{\text {max }}, d_{\text {max }}, d_{\text {max }}, d_{\text {max }}, d_{\text {max }}, d_{\text {max }}, d_{\text {max }}$ ".

In addition to this PDM, a hysteresis control is implemented. The selection of intermittent PDM and simple duty ratio control is carried out by the state transition map, as in Fig. 7. The hysteresis bandwidth is tuned by a trial and error approach so that the frequency response is acceptable, as 
later shown in Fig. 12, and the chattering frequency is not too large. All the symbols and variables are summarized in Table 2. Introduction of the hysteresis control prevents a frequent transition between the intermittent PDM and the simple duty ratio control, and control stability is improved. Moreover, we confirmed the stability of the total control loop by calculating the transfer function assuming that the plant is of a second order and PWM is a linear function. All poles are located in the left half plane.

\section{Verification of Intermittent Pulse Modulation}

In this section, the step and frequency response characteristics of the intermittent PDM and simple PWM controls were simulated using PSIM software and verified by several experiments. For the simple PWM control, the following algorithm was employed. When the duty ratio $d_{P I}$ from the PI controller in Fig. 6 is between 0.0 and 0.05 , the duty ratio $d_{\text {ref }}$ of Fig. 6 is set to 0.0 and when it is between 0.05 and 0.1 , it is set to 0.1 .

\subsection{Simulations of Steady State Operation}

\subsubsection{Simulation Conditions Figure 8 shows the} simulation circuit in which the load is replaced with a pure resistance. The circuit parameters are shown in Table $3^{(8)}$. A load resistance of $40 \Omega$ is assumed as the replacement of a motor load.

The hardware minimum duty ratio $d_{\min }$ is 0.06 ; however, in the actual experiments it was set to 0.1 for safety reasons. Thus, in this study the minimum duty ratio was set at 0.1 . The voltage reference was selected to be $113 \mathrm{~V}(d=0.01)$. The total number of samples in the averaging was set to 16 (= $n$ in (3) and (4)), and the pattern of intermittent output pulses

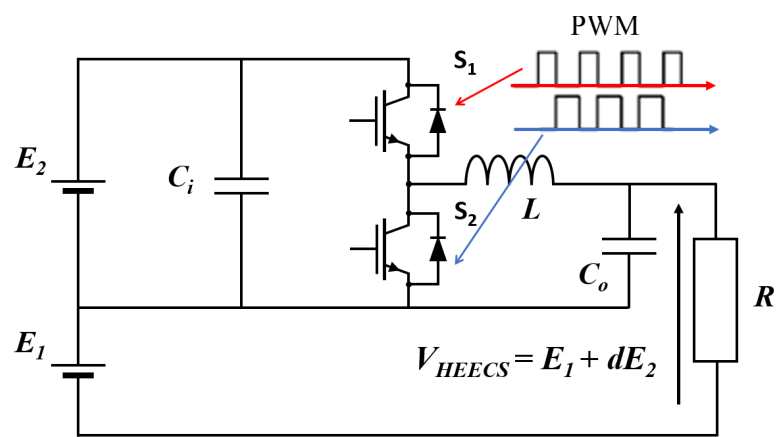

Fig. 8. Simulation circuit of intermittent PDM and simple PWM

Table 3. Specifications of HEECS chopper in simulations and experiments ${ }^{(8)}$

\begin{tabular}{|l|l|}
\hline Maximum output power & $10 \mathrm{~kW}$ \\
\hline Switch devices & SiC-MOSFET \\
\hline Rated output power & $5 \mathrm{~kW}$ \\
\hline Switching frequency & $60 \mathrm{kHz}$ \\
\hline Inductance $L$ & $78 \mu \mathrm{H}$ \\
\hline Input capacitor $C_{\mathrm{i}}$ & $50 \mu \mathrm{F}$ \\
\hline duty ratio reference & $d_{r e f}$ \\
\hline Output capacitor $C_{O}$ & $88 \mu \mathrm{F}$ \\
\hline Input voltage $E_{1}$ & $110 \mathrm{~V}$ \\
\hline Input voltage $E_{2}$ & $240 \mathrm{~V}$ \\
\hline Chopper weight $m$ & $5 \mathrm{~kg}$ \\
\hline
\end{tabular}

was taken from Table 1.

4.1.2 Simulation Results Figure 9(a) shows simulation results of steady state operation in which the inductor current ripple under the simple PWM control was lower than that under the proposed intermittent PDM control. This is because the switching frequency of the simple PWM $(60 \mathrm{kHz})$ was higher than that of the intermittent PDM $(60 / 16 \mathrm{kHz})$. Figure 9(b) shows the experimental result of the intermittent PDM. It is observed that the two waveforms of simulations and experiments are very similar under this control. Thus, it is verified that the proposed control is properly implemented in the experiments.

\subsection{Simulations of Step Response}

4.2.1 Simulation Conditions The simulation conditions were the same as in the previous section except that the voltage reference was changed stepwise from $112 \mathrm{~V}(d$ $=0.01)$ to $127 \mathrm{~V}(d=0.07)$, and the resistance value was changed from $4.42 \Omega$ to $4.28 \Omega$, simultaneously. This load parameter condition is aimed at replacement of a motor load condition from $23.1 \mathrm{~km} / \mathrm{h}$ and $137 \mathrm{Nm}$ to $26.9 \mathrm{~km} / \mathrm{h}$ and $123 \mathrm{Nm}$, which corresponds to the speed transition of a JC08 mode driving cycle from 1017 [s] to 1018 [s] ${ }^{(13)}$.

4.2.2 Simulation Results Figure 10 shows the simulation results of this step response; it is observed that the peak inductor current in the transient was suppressed more under the proposed intermittent PDM control than under the simple PWM control. However, a slight voltage overshoot occurred under both controls because the PI gain was adjusted to be optimal between $0.1<d<0.93$. If a lower PI gain is used, the peak current in the transient can be lower; however, it becomes difficult for the output voltage to follow the reference voltage and the vehicle speed cannot follow the speed refer-
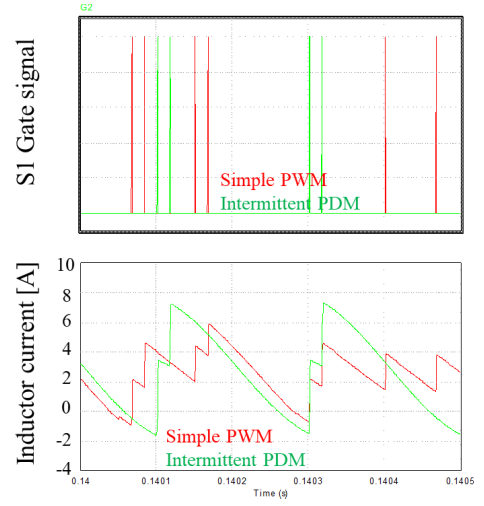

(a) Simulation Results

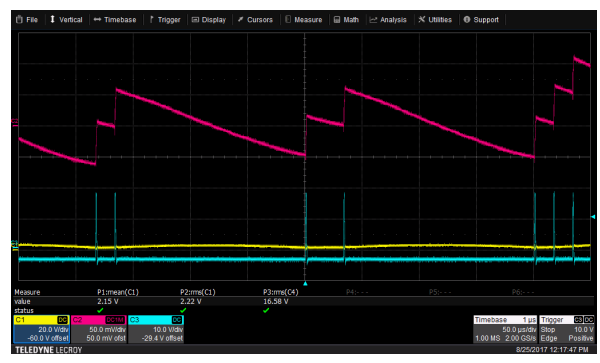

(b) Experimental Result (intermittent PDM)

Red line, yellow line, and blue line indicate inductor current, output voltage, and gate signal, respectively.

Fig. 9. Comparison of Intermittent PDM and simple PWM of Steady State 


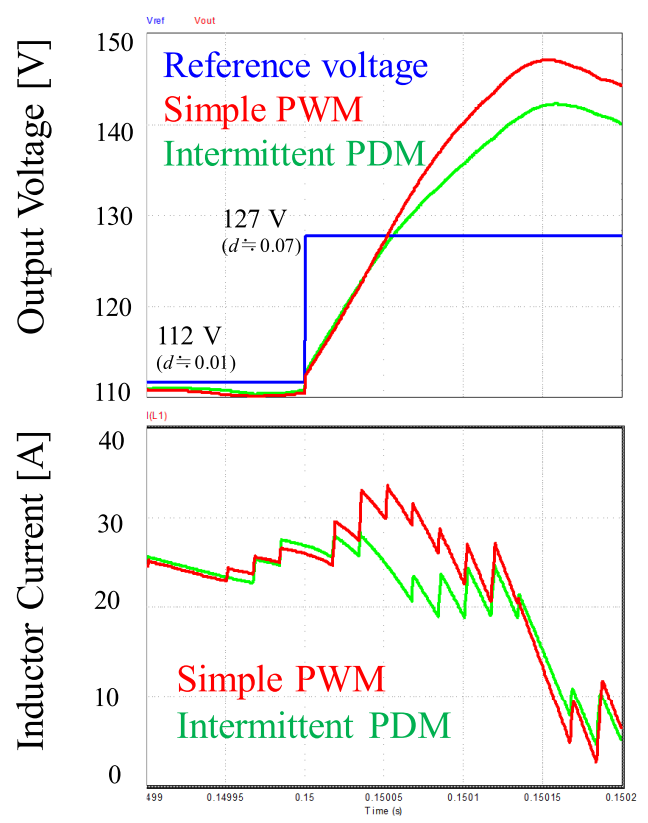

Fig. 10. Comparison of intermittent PDM and simple PWM of step response in simulations

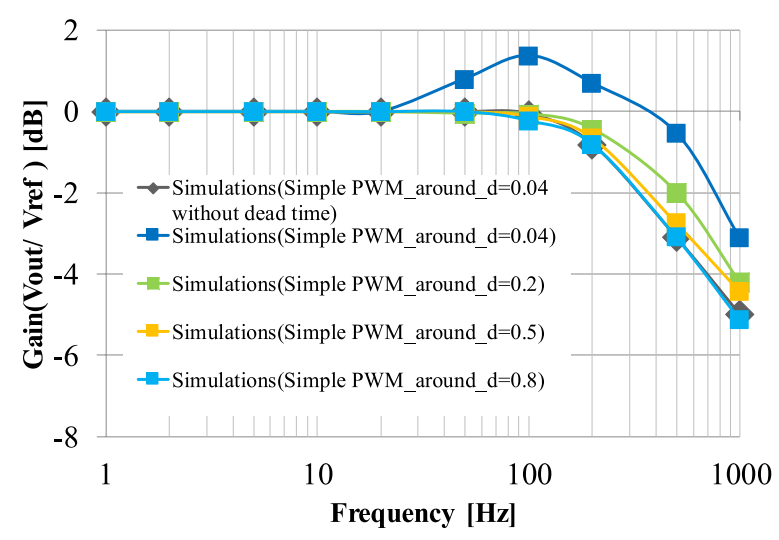

Fig. 11. Small AC signal Bode plot of simple PWM control at different average duty ratio in simulations

ence of the JC08 test cycles. It is also observed that the peak overshoot voltage under the proposed PDM is slightly lower than that of the simple PWM.

Thus, by using intermittent PDM, overcurrent is avoided, and the voltage response is not degraded in the step response.

4.3 Simulations of Frequency Response Characteris$\operatorname{tics}^{(14)-(16)}$

4.3.1 Simulation Conditions Simulation conditions were same as the previous section except for the resistance value, which was set to $40 \Omega$. This resistance value is aimed at the replacement of a load at $80 \mathrm{~km} / \mathrm{h}$ and $40 \mathrm{Nm}$.

To investigate the frequency response characteristics of the proposed intermittent control, the voltage reference is given as a sinusoidal wave with peak amplitude of $4 \mathrm{~V}$ and DC average values of $120 \mathrm{~V}$. This is equivalent to an average duty ratio of approximately 0.04 . The frequency characteristics (gain and phase) were measured by changing the frequency of the sinusoidal reference wave.

4.3.2 Simulation Results First, Fig. 11 shows a bode plot of simple PWM control simulation results. It is observed that the simple PWM control has a problem around a very

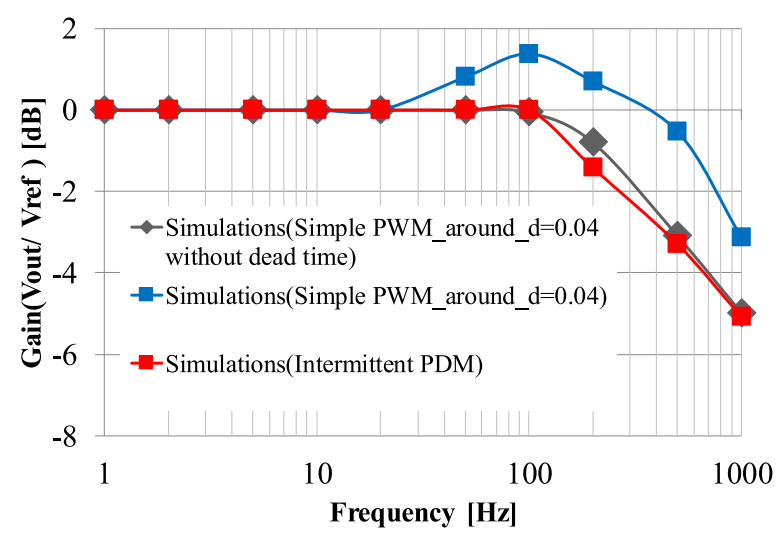

Fig. 12. Small AC signal Bode plot of intermittent PDM and simple PWM control around the duty ratio 0.04 in simulations
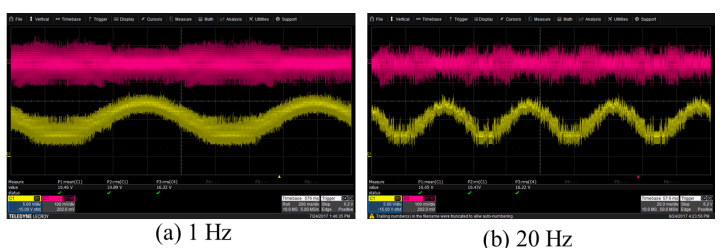

(b) $20 \mathrm{~Hz}$ (c) $50 \mathrm{~Hz}$

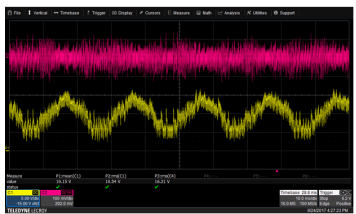

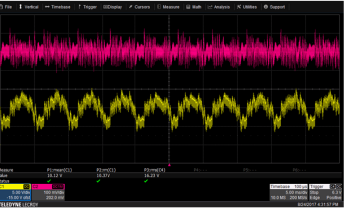

(d) $200 \mathrm{~Hz}$
Red line and yellow line show inductor current and output voltage.

Fig. 13. Sinusoidal response of intermittent PDM control in experiments

low duty ratio (0.04) as discussed earlier. The simple PWM without dead time in Fig. 11 indicates that the minimum pulse width $d_{\min }$ is zero because the no dead time condition results in no limitations to the minimum pulse width as described in Section 3.2. It is observed that the oscillation of the simple PWM with dead time around $100 \mathrm{~Hz}$ is suppressed by the simple PWM without dead time.

Second, Fig. 12 shows the comparison of the proposed intermittent control and the simple PWM control around a very small duty ratio $(\mathrm{d}=0.04)$. It is observed that the intermittent PDM controller has almost the same characteristics as the PWM for the duty ratio between 0.2 and 0.8 from Fig. 11 . Further, by using intermittent PDM, a response that is close to ignoring the switching dead time is obtained. These results demonstrate that the proposed controller guarantees the same frequency response characteristics of the original PWM control over all duty ratios.

4.4 Frequency Response Characteristics in Experiments ${ }^{(6)(15)}$

4.4.1 Experimental Conditions The experimental circuit is the same as in section 4.2. The reference DC value is selected to be $120 \mathrm{~V}$ and a small AC signal is chosen as $4 \mathrm{~V}$. The average duty ratio $d$ is approximately 0.04 .

4.4.2 Experimental Results Fig. 13 shows the small signal sinusoidal response of the chopper output voltage.

Figure 14 compares the frequency characteristics of the simulation and experimental results when the duty ratio is 


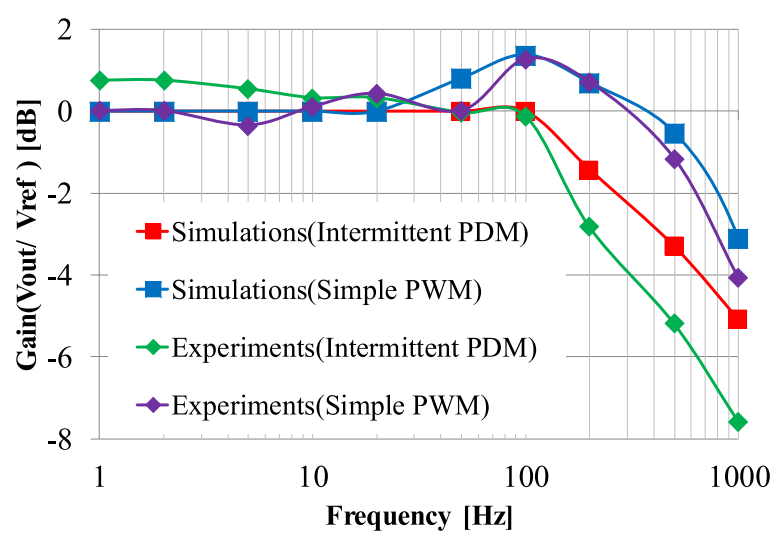

Fig. 14. Small AC signal Bode plot comparison of experiments and simulations around the average duty ratio 0.04

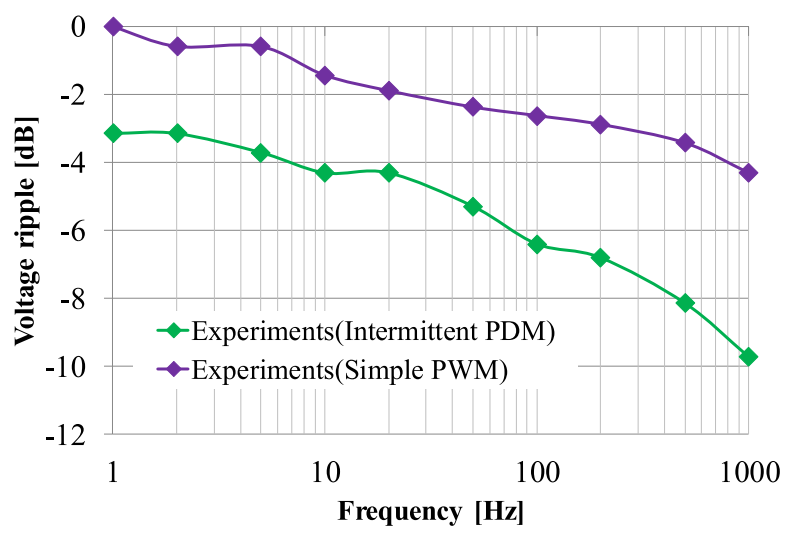

Fig. 15. Voltage ripple comparison of intermittent PDM and simple PWM control (Experiments)

The ratio reference value of $\mathrm{dB}$ is voltage ripple of the simple PWM control $(f=$ $1 \mathrm{~Hz})$.

very low $(d=0.04)$. The two sets of data match very well. Moreover, the frequency response at duty ratios between 0.2 and 0.8 in the simulations of Fig. 11 and in the experimental intermittent curve of Fig. 14 are very similar. These figures indicate that the proposed intermittent control makes the total frequency response of the output DC voltage PI controller more stable.

Figure 15 shows the voltage ripple frequency characteristics of the small AC reference when the duty ratio is very low $(d=0.04)$. This figure indicates that the ripple generated by the sudden change in the duty ratio around a very low duty ratio value is less in the proposed intermittent control than in the pure PI control. The effect of the proposed approach is apparently superior to the pure PI, in which the attenuation of the ripple is about $4 \mathrm{~dB}$, particularly around a frequency of $100 \mathrm{~Hz}$.

Therefore, it was confirmed that voltage ripple and current ripple were reduced by the proposed method, and the proposed voltage controller has almost the same frequency characteristics for all duty ratios.

\section{Experiments of Driving Range Extension based on Proposed Intermittent Pulse Density Modulation Control ${ }^{(6)}$}

5.1 Steady State Efficiency Map The steady state efficiency map of the proposed chopper-based power train was measured by using the motor test bench. We compared the efficiency of the power train of the proposed control with the non-chopper type.

The output voltage command of the HEECS chopper was changed according to (5) as a function of the motor speed $v$ $[\mathrm{km} / \mathrm{h}]$ and the non-chopper power train was always equal to $E_{1}+E_{2}$.

$$
V_{\text {HEECS }}=\left\{\begin{array}{cc}
E_{1} & (v \leq 22.7) \\
4.1875 v+15 & (v>22.7)
\end{array} \ldots \ldots \ldots \ldots\right.
$$

Measurements were taken from $10 \mathrm{~km} / \mathrm{h}$ to $80 \mathrm{~km} / \mathrm{h}$ by $10 \mathrm{~km} / \mathrm{h}$ steps and $-60 \mathrm{Nm}$ to $60 \mathrm{Nm}$ by $10 \mathrm{Nm}$ steps. Each overall efficiency $\eta_{\text {HEECS_total }}$ and $\eta_{\text {non_chopper_total }}$ is expressed as

$$
\begin{aligned}
& \eta_{H E E C S \_t o t a l}=\frac{\omega_{m} T_{m}}{P_{1}+P_{2}}, \cdots \\
& \eta_{\text {non-chopper_total }}=\frac{\omega_{m} T_{m}}{V_{\text {inv }} I_{\text {inv }}},
\end{aligned}
$$

where, $\omega_{m}, T_{m}, V_{I N V}$, and $I_{I N V}$ represent the motor angular velocity, the motor torque, the input voltage, and current of the inverter, respectively.

Figures 16(a) and (b) show efficiency maps of the nonchopper power train and the chopper-based power train. The figures show that the HEECS chopper-based power train has wider high efficiency area. Because inverter switching loss is proportional to the input voltage, the inverter efficiency is improved by changing the input voltage almost proportionally to the motor speed. Thus, the total efficiency of the HEECS chopper-based power train is also improved compared with the non-chopper type in all speed and torque domains.

5.2 Driving Range Extension based on Proposed Intermittent Pulse Density Modulation Control Energy consumption was measured in the driving mode test cycles ${ }^{(13)}$ by using the motor test bench, and the total energy was compared between the HEECS chopper-based power train and the non-chopper type power train ${ }^{(6)}$. The proposed intermittent PDM made it possible to run these kinds of driving test cycles. Without this control, overcurrent protection sometimes occurred, and the test cycles were often interrupted. The results are summarized in Table 4. Two types of driving mode tests were employed for this study: JC08 mode, 10-15 mode, WLTC low mode, and WLTC middle mode. The proposed power train saves approximately $5.3 \%$ energy in the JC0 8 mode, $6.3 \%$ in the $10-15$ mode, $6.4 \%$ in the WLTC low mode, and $1.9 \%$ in the WLTC middle mode compared with the non-chopper power train. These results imply that the proposed DC voltage control is more effective for driving in the city than driving on the highway.

\section{Conclusion}

A novel intermittent pulse density modulation method is proposed for the two-battery HEECS chopper, in which the pulse density is intermittently controlled so that the average duty ratio is equal to a reference value. The step response was simulated using the intermittent PDM and the inductor current was observed to be suppressed compared with the simple PWM control. The frequency characteristics were also measured for the HEECS chopper, and we confirmed that the total frequency characteristics of a PI controller are approximately 


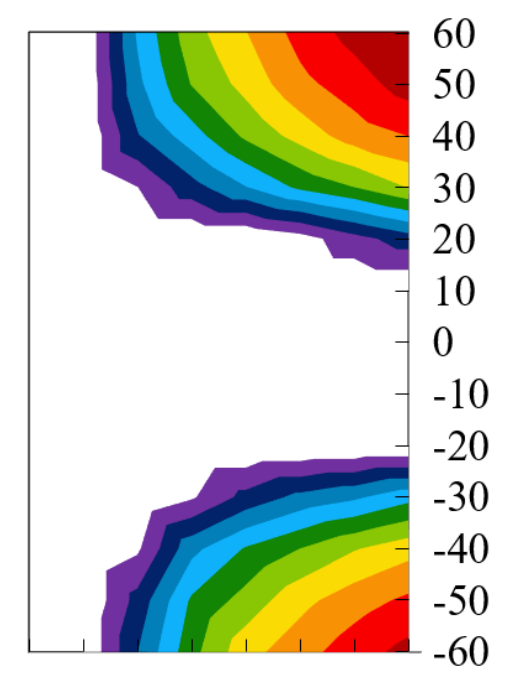

1020304050607080 Speed $[\mathrm{km} / \mathrm{h}]$

(a) Non-chopper type power train

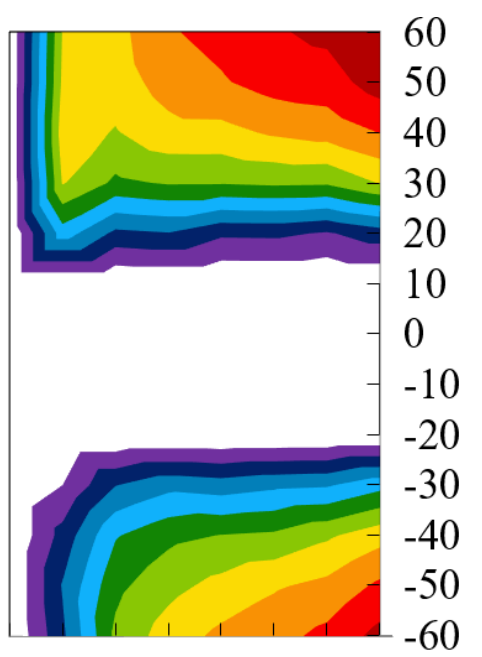

$89-90$

$88-89$

$87-88$

$86-87$

$85-86$

$84-85$

$83-84$

$82-83$

- 81-82

80-81

$-80$

Fig. 16. Comparison of efficiency measurement data in motor test bench

Table 4. Experimental results of energy consumption in the several kinds of test cycle

\begin{tabular}{|c|c|c|c|c|c|}
\hline & & Power train type & Energy consumption [Wh] & $\begin{array}{c}\text { Energy consumption } \\
\text { per } 1 \mathrm{~km} \text { traveling } \\
{[\mathrm{Wh} / \mathrm{km}]}\end{array}$ & Reduction ratio [\%] \\
\hline \multirow{8}{*}{ Test cycle } & \multirow{2}{*}{$\mathrm{JC} 08$} & Non-chopper & 251.3 & 30.7 & - \\
\hline & & Two-battery HEECS & 232.8 & 29.1 & 5.3 \\
\hline & \multirow{2}{*}{$10-15$} & Non-chopper & 123.5 & 29.6 & - \\
\hline & & Two-battery HEECS & 115.7 & 27.8 & 6.3 \\
\hline & \multirow{2}{*}{$\begin{array}{l}\text { WLTC } \\
\text { Low }\end{array}$} & Non-chopper & 91.9 & 29.7 & - \\
\hline & & Two-battery HEECS & 86.0 & 27.8 & 6.4 \\
\hline & \multirow{2}{*}{$\begin{array}{l}\text { WLTC } \\
\text { Middle }\end{array}$} & Non-chopper & 155.5 & 32.7 & - \\
\hline & & Two-battery HEECS & 152.7 & 32.1 & 1.9 \\
\hline
\end{tabular}

unchanged over the whole duty ratio range. Moreover, the voltage ripple is decreased. Using the proposed control, four driving cycle tests were performed in the motor test bench, and approximately $6.3 \%$ of energy savings was confirmed for the 10-15 driving mode cycle test.

\section{References}

( 1 ) Y. Ikezawa, H. Fujimoto, Y. Hori, D. Kawano, Y. Goto, M. Tsuchimoto, and K. Sato: "Range Extension Autonomous Driving for Electric Vehicles Based on Optimal Velocity Trajectory Generation and Front-Rear Driving-Braking Force Distribution", IEEJ J. Industry Applications, Vol.5, No.3, pp.228-235 (2016)

(2) A. Kawamura, G. Guidi, S. Tsutsuki, Y. Watanabe, Y. Tsuruta, and N. Motoi: "Experimental Data Analysis on Total Driving Performance of Series Chopper Based EV Power Train", Annual Conference of the IEEE Industrial Electronics Society (IECON), PP '1348-1353, Melbourne (2011)

( 3 ) K. Aoyama, N. Motoi, Y. Tsuruta, and A. Kawamura: "High Efficiency Energy Conversion System for Decreaces in Electric Vehicle Battery Terminal Voltage", IEEJ J. Industry Applications, Vol.5, No.1, pp.12-19 (2016)

( 4 ) M. Pavlovsky, Y. Tsuruta, and A. Kawamura: "Bi-directional buck/boost dcdc converter with ultra high efficiency based on improved SAZZ topology", Proc. of Energy Conversion Congress and Exposition, ECCE 2009, pp.17831790 (2009)

( 5 ) Y. Hosoyamada, M. Takeda, T. Nozaki, N. Motoi, and A. Kawamura: "High Efficiency Series Chopper Power Train for Electric Vehicles Using a Motor Test Bench", IEEJ Journal of Industry Applications, pp.460-468 (2015)
( 6 ) A. Tamura, K. Kobayashi, Y. Tsuruta, K. Kojima, H. Obara, and A. Kawamura: "Range Extension of Electric Vehicles by Two Battery HEECS Chopper based Power Train", ECCE2017-CINCINNATI-OHIO, pp.44884492, Cincinnati, Ohio, USA (2017)

( 7 ) S. Tenner, S. Guther, and W. Hofmann: "Loss Minimization of Electric Drive Systems Using a DC/DC Converter and an Optimized Battery Voltage in Automotive Applications", Vehicle Power and Propulsion Conference, pp.1-7 (2011)

( 8 ) Y. Tsuruta and A. Kawamura: "Principle verification prototype chopper using SiC MOSFET module developed for partial boost circuit system", IEEE Energy Conversion Congress and Exposition (ECCE), pp.1421-1426 (2015)

( 9 ) F. Xue, R. Yu, and A. Huang: "Fractional converter for high efficiency high power battery energy storage system", 2017 IEEE Energy Conversion Congress and Exposition (ECCE), Cincinnati, OH, pp.5144-5150 (2017)

(10) R.M. Button: "An advanced photovoltaic array regulator module", IECEC 96. Proceedings of the 31st Intersociety Energy Conversion Engineering Conference, Washington, DC, pp.519-524 (1996)

(11) T. Umihara, A. Tamura, T. Ishibashi, and A. Kawamura: "Proposal of SoC balancing methodology in 2 battery HEECS Power Train for Electric Vehicle", Proceedings of the Annual Conference of IEEJ, 4-087, Fukuoka, Japan (2018)

(12) T. Umihara, A. Tamura, T. Ishibashi, and A. Kawamura, "Proposal of Soft SOC Balancing Method to Two Battery HEECS chopper used for EV Power Train”, IECON2018, Washington D.C., USA (2018)

(13) TRIAS (Traffic Safety and Nuisance Research Institute's Automotive Type Approval Test Standards) 5-10-2008", Ministry of Land, Infrastructure, Transport and Tourism.

(14) A. Tamura and A. Kawamura: "Proposal of High Bandwidth Frequency Voltage Control for EV Power Train by Two Battery HEECS Chopper", IEE-Japan Industry Applications Society Conference, 4-7, Hokkaido, Japan 
(2017)

(15) A. Tamura, T. Ishibashi, and A. Kawamura: "Frequency Characteristic of Output Voltage Control by Introducing of Intermittent Pulse Density Modulation for Two Battery HEECS Chopper", IEE-Japan Industry Applications Society Conference, 4-5, Yokohama, Japan (2018)

(16) A. Tamura, T. Ishibashi, T. Umihara, Y. Tsuruta, H. Obara, and A. Kawamura: "Intermittent Pulse Density Modulation of Two Battery HEECS Chopper for Electric Vehicles", IECON2018, Washington D.C., USA (2018)

Ayataro Tamura (Student Member) received the B.E. degree in elec-

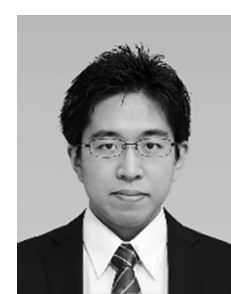
trical and computer engineering from Yokohama $\mathrm{Na}-$ tional University, Japan, in 2017. He is currently working toward the M.E degree. He has been with the Kawamura Laboratory at Yokohama National University since April 2016. His research interests include power electronics especially electric vehicle power train.

Takayuki Ishibashi (Student Member) received the B.E. degree in

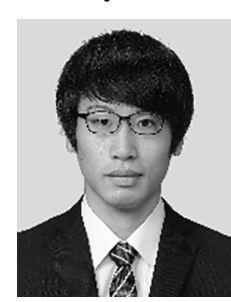
electrical and computer engineering from Yokohama National University, Japan, in 2018. He is currently working toward the M.E. degree. He has been with the Kawamura Laboratory at Yokohama National University since April 2017. His research interests include power electronics and electric vehicle.

Takuro Umihara (Student Member) is currently working toward the

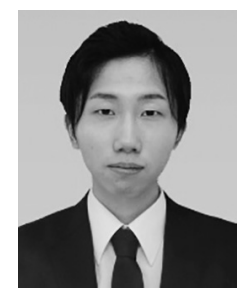
B.E. degree in electrical and computer engineering from Yokohama National University, Japan. He has been with the Kawamura Laboratory at Yokohama National University since April 2017. His research interests include power electronics and electric vehicle.
Yukinori Tsuruta (Member) received the B.S., M.S., and Ph.D. de-

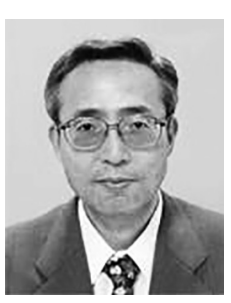
grees in electrical engineering from Yokohama National University, Yokohama, Japan, in 1975, 1977, and 2006, respectively. From 1977 to 2003, he was with Toshiba Corporation, Tokyo, Japan, working with the Design and Development Section of Power Converter Equipment as a Specialist Engineer in the Fuchu Works. He is currently with Yokohama National University as a Postdoctoral Fellow and a government-industry-academia collaboration researcher (Non-Full-time). His research interests are SiC converter for EV drive system and renewable energy generation system.

Hidemine Obara (Member) received the Ph.D. degree in electrical

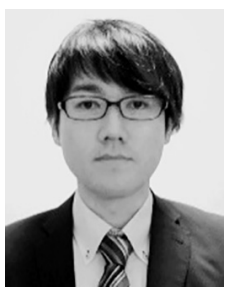
and electronics engineering from Chiba University, Japan in 2015. From Oct. 2015 to Mar. 2016, he was a postdoctoral researcher in Tokyo Metropolitan University. Since Apr. 2016, he has been with Yokohama National University as an assistant professor. His research interests include circuit topology, system integration, and implementation for multi-level power converters. Dr. Obara is a member of IEEE and IEE of Japan.

Atsuo Kawamura (Fellow) received the Ph.D. degree in electrical en-

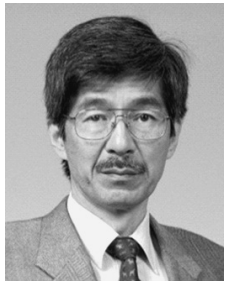
gineering from University of Tokyo in 1981. He then spent five years at University of Missouri-Columbia as a faculty member. Then he joined Yokohama National University in 1986, and now is a Professor. His research interests are in the fields of power electronics, digital control, electric vehicles, train traction control and robotics. He received Transaction Paper Award from IEEE in 1988, 2001, and 2002. Also, Kawamura is an IEEE and IEEJ Fellow. 